九州大学学術情報リポジトリ

Kyushu University Institutional Repository

\title{
Measures of Forest Sector Corresponding to the UNFCCC in Korea
}

Choi, Soo Im

Korea Forest Research Institute

Kang, Hag Mo

Gyeonggi-do Farest Environment Research Station

Lee, Sang Hyun

Faculty of Forest Science, Chonbuk National University

Sato, Noriko

Faculty of Agriculture, Kyushu University

https://doi.org/10.5109/9311

出版情報：九州大学大学院農学研究院紀要. 52 (1)，pp.249-254，2007-02-28. Faculty of Agriculture, Kyushu University

バージョン：

権利関係： 


\title{
Measures of Forest Sector Corresponding to the UNFCCC in Korea
}

\author{
Soo Im CHOI ${ }^{1}$, Hag Mo KANG ${ }^{2 *}$, Sang Hyun LEE $^{3}$ \\ and Noriko SATO
}

\author{
Laboratory of Forest Policy, Division of Forest Environment and Management Sciences, \\ Department of Forest and Forest Products Sciences, Faculty of Agriculture, \\ Kyushu University, Fukuoka 812-8581, Japan \\ (Received November 10, 2006 and accepted December 1, 2006)
}

\begin{abstract}
The purpose of this study was to investigate possible measures of domestic forest sector corresponding to the United Nations Framework Conventions on Climate Change (UNFCCC) in Korea and to examine the background of how these measures have been established. Most of the devastated forests have been afforested by the large-scale afforestation campaign in the 1970s through 1980s on a national level in Korea; for this reason, there have been very few places currently available for afforestation and reforestation. Therefore, the domestic forest policy in accordance with the UNFCCC should focus on how to ensure carbon sinks through forest tending activities (forest management) with the plan, in which 4.9 million ha of stand for production forest land are recognized as greenhouse gas (GHG) sinks by 2022 rather than on how to obtain them through afforestation. In addition, the methods of the afforestation of marginal agricultural land with low productivity and the formation and expansion of urban forest have been established to overcome the limitations of forest land area where afforestation could be performed. Furthermore, the policy of preventing forest disaster, controlling deforestation and expanding forest bio-energy and the use of wood products has been performed as the measures of carbon emission source. If such forest policies corresponding to the UNFCCC are proceeded while people are having a wide range of understanding on the public interest of forest, it is estimated that they will have a positive reaction.
\end{abstract}

\section{INTRODUCTION}

The Kyoto Protocol was adopted at COP3 (the Third Conference of the Parties) of the United Nations Framework Conventions on Climate Change (UNFCCC) in December 1997 and the function of forest was reassessed as a pool and sink of carbon dioxide, one of the primary causes in global warming. Not only did the Kyoto Protocol stipulate concrete details for reducing greenhouse gas (GHG) for developed countries, but also it started to recognize the amount of GHG absorption and emissions derived from the land-use changes such as afforestation, reforestation and deforestation (Article 3.3 of the Kyoto Protocol) and forest management (Article 3.4 of the Kyoto Protocol) with regards to forest sinks at the time of calculating it country by country (IPCC, 1997; UN, 1998). The Kyoto Protocol came to a crisis due to the nonattendance of the USA, the first ranked country GHG emissions; however, with the aid of Russia's ratification in November 2004 and it came into effect officially in Feb. 16, 2005 (Cho and Kang, 2006).

Meanwhile, the $9^{\text {th }}$ and $10^{\text {th }}$ ranked country in the amount of carbon dioxide emissions and the scope of energy consumption, respectively as of 2002, Korea joined the UNFCCC in December 1993 and ratified the Kyoto Protocol in November 2002. When the Kyoto Protocol was adopted, Korea did not belong to one of

1 Korea Forest Research Institute, Seoul, 130-712, Korea

2 Gyeonggi-do Forest Environment Research Station, Osan, 447-290, Korea

3 Faculty of Forest Science, Chonbuk National University, Chonju, 561-756, Korea

* Corresponding author (E-mail: kanghagmo@hanmail.net) the developed countries so that it was not mandatory for her to reduce GHG during the first commitment period (2008 to 2012). However, as the Kyoto Protocol has been effective, it has been considered that there would be continuous discussions on the methods of participation of some developing countries such as China, India and Mexico as well as Korea in mandatorily reducing GHG. Especially, it has been expected that Korea that has been one of the OECD members and excluded during the first commitment period would be under the severe pressure of taking the responsibility on mandatory reduction of GHG from the second commitment period (2013 to 2017) (KFRI, 2005b; Cho and Kang, 2006).

Under these circumstances, it has been assumed that the forest with the function of long-term sink of carbon dioxide has played an important position in complying the mandatory reduction of GHG for each country by the Article $3.4 \& 3.5$ of the Kyoto Protocol. Japan set the goal of reducing $6 \%$ of the amount of GHG emissions compared to the counterpart in 1990, among which 3.9\% (13 million tC) would be reduced by forest improvement activities) (Kobayashi, 2004).

Therefore, the purpose of this study is to examine the measures of domestic forest sinks and source (using forest bio-energy) for reducing the GHG corresponding to the UNFCCC and to investigate the background of how these policies have been established and the prospective methods in forest policy in Korea.

\section{METHODS OF STUDY}

This study looked into the present conditions of GHG emissions in Korea and governmental measures 
with regards to the UNFCCC based on the statistics on the amount of GHG provided by governmental authorities and the materials and reports concerning climate change. Next, it examined the field-by-field characteristics of "basic plan on the expansion of carbon sinks" established by Korea Forest Service (KFS) so as to figure out the measures of domestic forest organizations corresponding to the UNFCCC and it also investigated the background of how the plan has been established.

\section{RESULTS AND DISCUSSION}

\section{Present Conditions of GHG Emissions in Korea}

Korea was ranked the $9^{\text {th }}$ in the world in the annual amount of GHG emissions as of 2002 and it has been on the increase most rapidly among the OECD countries (IEA, 2004). It has kept increasing due to its continuous economic growth and energy consumption-oriented industry structure since 1990, but it has been gradually slowing recently. Nevertheless, its annual increase from 1990 to 2002 reached 5.1\% (Table 1) (Oh and Jung, 2005).

The scope of the amount of GHG emissions amounted to 154,724 thousand tC as of 2002; among them the net amount of their emissions excluding 9,793 thousand tC, the amount of sinks such as through Land Use, Land-Use Change and Forestry (LULUCF), reached 144,930 thousand tC. In terms of industry category, the energy field amounted to 129,013 thousand tC, which formed $83.4 \%$ of the entire amount of emissions, and it was followed by industrial process $(10.9 \%)$, agriculture (2.9\%) and waste matters (2.8\%).

\section{Governmental Measures Regarding the Compliance of the UNFCCC in Korea}

Korea was classified as one of the developing countries in 1995 in the UNFCCC judged from the status at the time of joining the OECD and she has belonged to Non-Annex I and did not satisfy the absolute amount of mandatory reduction in GHG required in developed countries to date. However, Korea founded a "Conference of Ministers Relevant to Global Environment" in August 1992 so as to comply with the comprehensive issues regarding the UNFCCC and global environment. Since then, its function was suspended in June 1995 and it was eventually abolished in accordance with the policy of reducing the governmental commit- tees in June 1996. As a consequence, the establishment and promotion of continuous and consistent governmental measures in compliance with the UNFCCC has been severely interrupted.

Afterwards, as the UNFCCC has progressed most rapidly in international society among the issues regarding global environment, it would be necessary to establish an organization on a national level for the systematic adjustment and practice of domestic measures under the assumption that there would be considerable troubles in the establishment and promotion of consistent measures corresponding to the UNFCCC. Besides, the Kyoto Protocol was adopted while determining the mandatory obligation on reducing GHG by developed countries at COP3 of the UNFCCC held in December 1997 in Kyoto, Japan and their pressures to participate in reducing GHG voluntarily have started to be given to some developing countries such as Korea. Accordingly, the "Government Organization in Preparation for the UNFCCC", in which relevant governmental authorities, universities, industries and research organizations participated, was founded in April 1998 by the instructions from the prime minister to prepare active measures on a governmental level corresponding to the UNFCCC. In December 1998, the "first comprehensive measure corresponding to the UNFCCC (1999 to 2001)" that synthesized various governmental policies and measures to reduce carbon dioxide. In March 2002, "the $2^{\text {nd }}$ comprehensive measure corresponding to the UNFCCC (2002 to 2004) was established with the following main points: strengthening an ability to negotiate in preparation for the discussion on mandatory responsibility (on the reduction of $\mathrm{GHG}$ ), improving the measure to reduce GHG, establishing and utilizing a foundation corresponding to the Kyoto mechanism and leading people's cooperation and participation in the UNFCCC (KEI, 2003). In February 2005, Korea established "the $3^{\text {rd }}$ comprehensive measure corresponding to the UNFCCC" while focusing largely on three fields such as project for establishing commitment base of the UNFCCC, project of reducing GHG for each section and project of establishing the adjustment to climate change by investing a total of 21 trillion and 500 billion won for three years in the future so as to prepare the effectuation of the Kyoto Protocol (Cho and Kang, 2006). Among the contents of the $3^{\text {rd }}$ comprehensive measure corresponding to the UNFCCC, the following elements were included: the dis-

Table 1. National GHG emissions from 1990 to 2002

\begin{tabular}{|c|c|c|c|c|c|c|}
\hline Classification & 1990 & 1995 & 2000 & 2001 & 2002 & $\begin{array}{c}\text { Growth \% } \\
(1990-2002)\end{array}$ \\
\hline Total & 84,738 & 123,445 & 144,252 & 148,028 & 154,724 & 5.1 \\
\hline Energy & 67,657 & 101,490 & 119,594 & 123,537 & 129,013 & 5.5 \\
\hline Industrial process & 5,428 & 12,747 & 15,886 & 15,748 & 16,929 & 9.9 \\
\hline Agriculture & 4,798 & 4,917 & 4,519 & 4,405 & 4,414 & -0.7 \\
\hline LULUCF (Sink) & $-6,476$ & $-5,793$ & $-10,156$ & $-9,448$ & $-9,793$ & 3.5 \\
\hline Waste & 6,945 & 4,291 & 4,254 & 4,337 & 4,367 & -3.8 \\
\hline Net Emissions & 78,262 & 117,651 & 134,096 & 138,530 & 144,930 & 5.3 \\
\hline
\end{tabular}

Source: Korea Energy Economics Institute. 2005 
tribution of technology and information for the enlargement of forest sinks in Clean Development Mechanism (CDM) project and their expansion through making up forest tending and urban forest and the prevention of forest insect pests and reinforcement of the prevention of forest fire (KFRI, 2005a).

\section{Measures in Forest Sector}

\section{Removals of Carbon Dioxide in Forest Sector}

The amount of carbon dioxide removed by the forest in Korea reached approximately 10,401 thousand tC as of 2003. However, among the net removals of carbon dioxide by the forest, only some could be recognized by the Kyoto Protocol. In 2000, the annual net removals of carbon dioxide reached 11,299 thousand tC, but the removals of forest that could be actually acknowledged by the Kyoto Protocol amounted to only approximately 200 thousand tC, which formed 1.8\% of the entire net removals (Table 2) (KFRI, 2005a).

Accordingly, KFS has performed an expansion project for carbon sinks; by doing so, it has established a goal, with which 8.1 million tC of removals of carbon dioxide, $93.1 \%$ of the annual net removals in 2020, would be acknowledged under the Kyoto Protocol. In order to accomplish the goal, KFS has been planning two forest policy projects. First, it will make efforts so as for 6.25 million ha (for stocked forest land) of the entire forest area in Korea to be recognized as a sink of GHG by 2022 through forest management project. Second, it will ensure 150,000 ha of the base of carbon sinks through overseas forest plantation through overseas joint cooperation by 2017 . The goal of net removals of carbon dioxide through the first and second projects amounts to 7.15 million tC and 1.5 million tC, respectively (KFS, 2005; KFRI, 2005b).

Table 2. Removals and Emissions of Carbon Dioxide by Forest

\begin{tabular}{cccc} 
& & & (Unit: 1,000 tC) \\
\hline Year & Net Removals & Total Removals & Emissions \\
\hline 2000 & 11,299 & 12,333 & 1,034 \\
2001 & 10,610 & 11,569 & 959 \\
2002 & 10,293 & 11,286 & 993 \\
2003 & 10,401 & 11,401 & 1,120
\end{tabular}

Source: Korea Forest Research Institute. 2005

\section{Basic Plan for Expanding Carbon Sinks}

KFS established "a basic plan for expanding carbon sinks," in which there were forest tending, afforestation of marginal agricultural lands, expansion of urban forest, prevention of forest disaster and control of de-forestation so as to comply effectively with the $3^{\text {rd }}$ comprehensive measure corresponding to the UNFCCC in 2005. In addition, it included overseas forest plantation in preparation for utilization projects of wood products and biomass and CDM plantation project in the said plan. Its detailed contents were as below (Fig. 1) (KFS, 2005). Forest Tending

Forest tending project is to raise ecologically sound

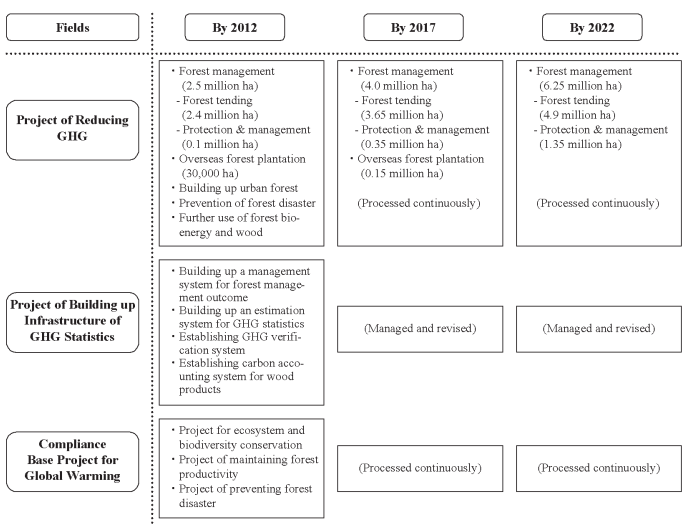

Fig. 1. Basic Plan for Expanding Carbon Sinks. Source: Korea Forest Service. 2005

forest in accordance with the basic principles of consistent forest management and to conserve and manage it so as for its public and socio-economic interests to be demonstrated as much as possible for the constant development of our society. It is linked to the method of ensuring carbon sinks because it can be recognized as the forest management activity specified in Article 3.4 of the Kyoto Protocol.

Forest forms $64 \%$ among the territory in Korea; however, most of the forest resources are less than 30 years old; therefore, it is necessary to manage them continuously in the future. Accordingly, KFS has proceeded with the forest tending project for 4.9 million ha of stands for production forest land with no limitations on forest management in accordance with the project of "Forest tending during the ten-year term"; in addition, it has had a plan to be completed by 2022 in a long run so as to be acknowledged as a forest sink for GHG (Table 3). In order to do this, it is going to raise additional revenue sources for the expansion of forest tending and to provide forest owners with economic incentives such as low-rate taxation. Besides, Korea Forest Service plans to establish an infrastructure for forest management for 1.35 million ha of stands for non-production forest land with the limitations on forest tending such as park areas, protection areas for cultural properties and water supply source. Meanwhile, it is necessary to maximize environmental and public interest-oriented functions such as the expansion of carbon sinks, air purification and improvement of water content along with the increase in growing stock through continuous forest tending in the future.

\section{Afforestation}

Korea has very limited forest areas, which could be recognized as forest sinks by afforestation and deforestation of the Article 3.3 of the Kyoto Protocol, by finishing up the Forestry conservation and afforestation during the first 10 year term and during the second 10 year term (1973 to 1987) and the $3^{\text {rd }}$ forest resource plan (1988 to 1997) successfully (Kim, 2004). Therefore, KFS plans to promote afforestation for mar- 
Table 3. Forest Tending Project Plan

(Unit: 10,000 ha)

\begin{tabular}{lccccc}
\hline \multirow{2}{*}{ Classification } & $2000-2003$ & \multicolumn{2}{c}{$1^{\text {st }}$ stage } & $2^{\text {nd }}$ stage & \begin{tabular}{c}
$3^{\text {rd }}$ stage \\
\cline { 3 - 4 }
\end{tabular} \\
\cline { 3 - 4 } $\begin{array}{l}\text { Amount of } \\
\text { annual project }\end{array}$ & 16 & $2004-2008$ & $2009-2012$ & & $2013-2017)$
\end{tabular}

Source: Korea Forest Service. 2005

ginal agricultural lands with disadvantageous farming conditions and low productivity and to expand carbon sinks through the enlargement of urban forest and trees on either side of a street. Currently, it is estimated that such marginal agricultural lands amount to 206,000 ha among the agricultural lands outside the agricultural development land. KFS plans to build up a measure to remove legal and systematic obstacles that impair voluntary forest plantation in consultation with the Ministry of Agriculture and Forestry regarding forest plantation of marginal agricultural lands. Besides, it is planning to make up small-scale urban forest, school forest, forest park and trees on either side of a street through the link to relevant governmental authorities and private organizations.

Protection of Forest Disaster and Control of Forest Damage

KFS has planned a measure to protect forest disaster and control forest damage because forest disaster and deforestation into other purposes would become primary causes of the emissions of carbon sinks. It plans to minimize the areas of forest loss through scientific prevention of forest fire and extinguishment of fire in its initial stage and to strengthen a predicting function against forest insect pests and to control the expansion of damaged areas by the prevention of insect pests in a suitable time. Besides, KFS is planning to expand a soil erosion control project, control deforestation systematically and restore it as rapid as possible when it is damaged so as to prevent landslide from taking place and to minimize flood damage. Especially, forest has formed $65 \%$ of our territory; however, it has been deforested to be used in other purpose in the process of industrialization and urbanization every year so that entire forest areas have been constantly on the decrease. The annual average of 7,000 ha of forest has been deforested so as to be used as roads, building sites, factories and so on. Therefore, KFS plans to set up a standard for nature-oriented forest development in order to minimize environmental damages in the aftermath of its development.

Overseas Forest Plantation

We plan to ensure 1.5 million tC of carbon sinks by 2017 through the overseas forest plantation by overseas joint cooperation project. In order to achieve this goal, we are going to conduct 150,000 ha of overseas forest plantation in a form of CDM and JI (Joint Implementation) projects. The qualifications and verification conditions of CDM project by afforestation and reforestation are strict and have no negative factors environmentally and socio-economically; for this reason, commercial projects such as wood production are relatively disadvantageous as much as our overseas forest plantation by far.

Meanwhile, the restoration of waste lands in North Korea satisfies most of the said such qualifications and their area is vast and amounts to approximately 1.6 million ha and is characterized by the establishment of North Korea's infrastructure in preparation for Korea's unification; therefore, it is appropriate to do it with the CDM project. However, there are many limitations in North Korea's CDM project with the subject of forest waste lands. In the same reason as Korea has not belonged to a country with mandatory obligation to reduce GHG in the UNFCCC, the qualified countries that can conduct a CDM forest project should be limited to the countries that have ratified the UNFCCC and the Kyoto Protocol. However, It is not possible to perform a CDM project for North Korea because it has not ratified the UNFCCC and the Kyoto Protocol (Kim, 2004; KFRI, 2005a).

Expansion of the Use of Wood Products and the Utilization of Forest Bio-Energy

According to Article $3.3 \& 3.4$ of the Kyoto protocol, the carbon stored in wood products will not be recognized, but only the carbon stored in forest will be recognized and calculated from the carbon sinks in forest during the first commitment period (2008 to 2012) (IPCC, 1997). That is to say, the current point of time for cutting forest has been defined as the point of time for emitting carbon when calculating the emissions and removals of carbon for each country. However, in various international conferences regarding the UNFCCC, there have been continuous debates on whether the carbon stored in wood products should be included in the inventories of the emissions and removals of carbon for each country (UNFCCC, 2003). As a result of future negotiations, the use of wood products and wood fuels will have tremendous influence on the reduction capability of carbon credit in forest field.

Therefore, KFS plans to diminish the use of fossil fuel in other fields by expanding the collection and utilization of products obtained from forest tending and utilizing them actively for the reduction of carbon emissions through the application of forest bio-energy and expansion of the use of wood products. It is estimated that the amount of products obtained from forest tending is approximately 1.6 million $\mathrm{m}^{3}$ annually; how- 
ever, the amount of its collection and use reaches $660,000 \mathrm{~m}^{3}$, which forms about 41\% (KFS, 2005). Meanwhile, it is going to maximize the use of wood products, to limit carbon emissions through the development of usage such as construction materials and the recycling of waste wood resources and to conduct continuous researches for the use of forest bio-energy.

Establishment of Database Concerning the Statistics on $G H G$

KFS is going to establish a verification system of the statistics on greenhouse gases corresponding to the Kyoto Protocol equivalent to Intergovernmental Panel on Climate Change (IPCC) Good Practice Guidance for Land Use, Land-Use Change and Forestry (GPG-LULUCF), which is an international standard, by 2011, deadline for statistics system for GHG, during the second commitment period of the Kyoto Protocol (Lim and Lee, 2004). In order to do this, it plans to build up various statistical data first for stand for production forest land where forest management is conducted and to make it possible to conduct a data management linked to the Forest Geographic Information System and to use a 'search' function. In addition, KFS is going to build up a database linked to the data regarding growing stock and soil and an estimation system for GHG for the calculation of accurate carbon stock. In order to do them, it plans to build up a monitoring system to check the change in growing stock and carbon stored in soils based on the survey system of the $5^{\text {th }}$ national forest resources starting in 2006 and to develop a conversion coefficient for carbon for the entire tree. In addition to this, it plans to establish an information verification system by analyzing information on forest resources and their change on a national level with the aid of a remote exploration technique using satellite image data. Besides, it is going to examine import-export and domestic distribution data for each type of wood products by embodying the carbon accounting system for wood products (KFS, 2005).

Researches on Forest Sector

Korea has been currently classified as one of the developing countries that has not taken mandatory responsibilities for reducing GHG; therefore, main researches on forest field have been in their initial stage in terms of the establishment of statistical foundation on GHG, technical assessment of their absorption, existing forest policies and their management analysis, methods of ensuring overseas carbon credit and emission trading (ET). Nevertheless, such researches have been performed mainly by Korea Forest Research Institute together with other research organizations (Lee, 2004a, 2004b).

The researches on the establishment of statistical foundation on GHG in Korea have been done through the statistical and systematic analysis of forestry activities, establishment database and calculation of removals and emissions of GHG in each activity that have been recognized by the Kyoto Protocol based on IPCC guideline and GPG-LULUCF. The research on the methods of ensuring overseas carbon credit has been conducted by analyzing the scenarios for plantation both in developing and developed countries and by assessing the appropriateness of small-scale experimental projects and economic feasibility (Bae, 2006; Lee and Jung, 2006). Besides, there have been also researches on the establishment of measures for domestic commitment systems such as ET and carbon tax. With regards to forest policy and management, there have been ongoing analyses on the present commitment conditions of relevant regulations and system and future plans for primary policies and managements concerning the removals and emissions of GHG such as forest tending, control of forest insect pests, forest fire management, control of deforestation and building up urban forest. There have been also researches on the change of forest ecosystem by evaluating how a carbon dioxide index and climate change would affect forest ecosystem.

\section{CONCLUSIONS}

Most of the devastated forests have been afforested by the large-scale afforestation campaign in the 1970s to 1980s on a national level in Korea; for this reason, there have been very few places currently available for afforestation and reforestation. On the other hand, 7,000 ha of mountainous areas have been used annually on the average for other purposes such as roads, building sites and so forth; therefore, it has been assumed that it would be hard to expand forest areas further. Besides, considering the current situation when forestry activities, especially cutting activities have not been done actively, it has been considered that it would not be possible to reduce GHG to a great extent by afforestation in the future. Accordingly, the characteristics of forest policy in compliance with the UNFCCC in Korea should focus on the method of ensuring carbon sinks not through afforestation stipulated in Article 3.3 of the Kyoto Protocol, but through the continuous forest tending activities (forest management) for current forest, with which 4.9 million ha of stand for production forest land should be recognized as the sinks of GHG by the year 2022. In addition, a method of building up afforestation of marginal agricultural lands with disadvantageous farming conditions and low productivity and the expansion of urban forest was established to overcome the limitations of forest areas where afforestation can be conducted. Furthermore, as one of the methods for carbon source, the policies of collecting and using forest tending and promoting the use of wood products have been conducted.

Meanwhile, it has been estimated that urban forest would be expanded a lot further when considering the effect of reducing additional GHG with the aid of building up urban forest in terms of its establishment policy, that is, the effect of reducing air-conditioning power consumption to some extent and its resultant effect of diminishing the amount of carbon dioxide emissions. Furthermore, it has been supposed that there would be many fields with low profitability in terms of the policy on the use of forest bio-energy so that it would be rea- 
sonable to create relevant services after judging cost effectiveness, to review the taxes on carbon that has been introduced in EU countries and to examine the supplement and tax breaks for the use of forest biomass energy.

If the measures of forest in compliance with the UNFCCC as shown above are proceeded with the policies that let people have a wide range of understanding on forest on behalf of public interest, it is assumed that the ongoing plan of expanding carbon sinks will have a positive reaction.

\section{REFERENCES}

Bae, J. S. 2006 Understanding Afforestation and Reforestation Project Activities under the Clean Development Mechanism in the First Commitment Period of the Kyoto Protocol. Korean. J. For. Economics, 14 (1): 59-76

Cho, Y. S and Y. Y. Kang. 2006 Analysis of Greenhouse Gas Emissions Allocation Schemes for OECD Countries. J. Environment Policy, 5 (1): 1-23

Intergovernmental Panel on Climate Change (IPCC). 1997 Revised 1996 IPCC guidelines for national greenhouse gas inventories. J. T. Houghton, L. G. Meira Filho, B. Lim, K. Treanton, I. Mamaty, Y. Bonduki, D. J. Griggs and B. A. Callander (eds.) Intergovernmental Panel on Climate Change, Meteorological Office, Bracknell, United Kingdom.

International Energy Agency (IEA). 2004 KEY WORLD ENERGY STATISTICS 2004

Kim, J. S. 2004 Strategies for the Domestic Forestry on the Framework Convention on Climate Change, Korean. J. For. Economics, 12 (2): 58-67

Kobayashi, N. 2004 Global Warming and Forest Business. Japan Forest Investigation Committee.

Korea Environment Institute (KEI). 2003 Establishment of a
Comprehensive Plan for Environmental Sector in Preparation for the UNFCCC

Korea Forest Service (KFS). 2005 Forum on Forest Policy Regarding the UNFCCC

Korea Forest Research Institute (KFRI). 2005a Global Warming, the UNFCCC and Forest; Role of Forest in Preparation for the UNFCCC

Korea Forest Research Institute (KFRI). 2005b Methods of Ensuring Forest Sinks domestically and internationally in Preparation for the UNFCCC. Data collection from Symposiums

Lee, K. H. 2004a Domestic and International Current Researches on Forest Sector in Preparation for the UNFCCC (1); Domestic Researches and Characteristics of Future Researches. Forest Science Information, 154: 14-15

Lee, K. H. 2004b Domestic and International Current Researches on Forest Sector in Preparation for the UNFCCC (2); Domestic Researches and Characteristics of Future Researches. Forest Science Information, 155: 14-15

Lee, S. Y and J. H. Jung. 2006 A Study on a Methodology for Economic Feasibility of A/R (Afforestation/Reforestaion) CDM (Clean Development Mechanism) -Case Studies on Temperate Humid Zone and Tropical Rain Forest Zone-. $J$. Environment Policy, 5 (1): 25-43

Lim, J. K and K. H. LEE. 2004 A Study on Establishing a Foundation for Drawing up the $3^{\text {rd }}$ National Report to the UNFCCC (first year); A Feasibility Analysis of IPCC Good Practice Guidance for Land Use, Land-Use Change and Forestry in the Drawing up the Statistics of Greenhouse Gases in Forestry. Korea Energy Economic Institute

Oh, S. H and T. Y. Jung. 2005 Climate Policy in Republic of Korea. Working Paper Series 2004 2005. Institute for Global Environment Strategies (IGES)

United Nations Framework Conventions on Climate Change (UNFCCC). 2003 Estimation, Reporting Accounting of Havested Wood Products. FCCC/TP/2003/7

United Nations (UN). 1998 Kyoto Protocol to the United Nations Framework Convention on Climate Change 